\title{
Saint-Réal, Césarion ou entretiens divers. Introduction et édition critique de Federico Corradi
}

Barbara Piqué

\section{(2) OpenEdition}

\section{Journals}

\section{Edizione digitale}

URL: http://journals.openedition.org/studifrancesi/1141

DOI: 10.4000/studifrancesi. 1141

ISSN: 2421-5856

\section{Editore}

Rosenberg \& Sellier

\section{Edizione cartacea}

Data di pubblicazione: 1 novembre 2014

Paginazione: 592-593

ISSN: 0039-2944

\section{Notizia bibliografica digitale}

Barbara Piqué, « Saint-Réal, Césarion ou entretiens divers. Introduction et édition critique de Federico Corradi », Studi Francesi [Online], 174 (LVIII | III) | 2014, online dal 01 novembre 2014, consultato il 18 septembre 2020. URL : http://journals.openedition.org/studifrancesi/1141 ; DOI : https://doi.org/ 10.4000/studifrancesi. 1141

Questo documento è stato generato automaticamente il 18 settembre 2020.

\section{(c) (i) $\odot$}

Studi Francesi è distribuita con Licenza Creative Commons Attribuzione - Non commerciale - Non opere derivate 4.0 Internazionale. 


\title{
Saint-Réal, Césarion ou entretiens divers. Introduction et édition critique de Federico Corradi
}

\author{
Barbara Piqué
}

\section{NOTIZIA}

Saint-Réal, Césarion ou entretiens divers. Introduction et édition critique de Federico CORRADI, Paris, Hermann, «Bibliothèque des Littératures Classiques», 2013.

1 Noto soprattutto come autore di quel Dom Carlos che, attraverso Schiller, ispirerà uno dei maggiori capolavori verdiani, Saint-Réal è scrittore ben più ricco e complesso, la cui ampia produzione illustra gli esiti estremi della «demolizione dell'eroe» portata avanti, nella seconda metà del Seicento, dalle forze congiunte del pessimismo agostiniano e di un neoepicureismo che, in forme diverse, mette anch'esso a nudo la miseria hominis.

Introdotto e annotato da Federico Corradi, Césarion, apparso anonimo da Barbin nel 1684, appartiene appunto alla vasta produzione di Saint-Réal, al cui centro vengono a congiungersi - forse anche sullo sfondo dell'incipiente Querelle des Anciens et des Modernes - riflessione morale (intesa come riflessione etica in senso stretto e riflessione sulla politesse mondana, non sempre sovrapposte, ricordiamolo, nella trattatistica secentesca) e riflessione sulla storia: ovverosia una rielaborazione e discussione dei luoghi - degli «spazi» - comuni più caratteristici, o, meglio, più caratterizzanti del tardo Rinascimento e del Seicento: da Machiavelli a Montaigne, da Descartes a Faret fino ai grandi moralisti e ai trattatisti francesi degli arts de vivre.

Nel 1671 Saint-Réal pubblica De l'usage de l'histoire. Del metodo storico che questo testo proponeva, Césarion, come osserva Corradi, è la migliore messa in opera: quel metodo si voleva "anatomie spirituelle des actions humaines», definizione dove la metafora stessa dell'anatomie, prediletta dalla scrittura morale, denunciava il legame stretto tra storia e analisi morale. Césarion consiste in quattro dialoghi, svolti in quattro Journées, 
tra il personaggio eponimo, alter ego di Saint-Réal, e un «je» che vale per un giovane «apprendista» del theatrum mundi, teatro passato e presente ma immutato e immutabile, come ricorderà di lì a poco il teofrasteo La Bruyère. La forma, il dialogo seppur di ascendenza antica e umanistica -, appartiene ai generi mondani impostisi nel secondo Seicento di contro ai trattati di stampo erudito: la «conversation», gli «entretiens» (termine che non a caso compare nel sottotitolo), la "promenade» ecc. La «scena di enunciazione» - nel senso dato alla formula da Dominique Maingueneau riprende lo sperimentatissimo topos della dimora di campagna, dove il padrone di casa, tra giardino, «cabinet» e "galerie» intrattiene gli ospiti (in questo caso il suo ospite) passeggiando, discorrendo, commentando. Anche la persona del «maitre des lieux» rinvia a una topica rivisitata secondo prospettive diverse: Césarion è un «courtisan désabusé» che, nella sua «retraite», all'otium litteratum - qui, in particolare, la lettura di Cicerone - affianca l'amara visione del mondo di chi nel mondo ha vissuto. Se Césarion può chiosare il grande scrittore latino con tanta acutezza, è perché ha fatto dal vivo, nell'oggi, l'esperienza di quella parola antica. Ed è in questa duplice figurazione che Césarion compone il proprio ethos di moralista mondano e di storico erudito.

Ma la novità del testo di Saint-Réal sta nella radicalità dell'operazione di smascheramento dei valori ancorati - per quanto già da più parti invalidati - nella cultura dell'epoca: dalla messa a nudo degli eroi della storia (donde l'uso prevalente di contro exempla) allo scaccomatto inflitto al viver civile professato nell'«honnêteté mondaine», contraria alla natura; dallo smantellamento dell'ideale di storia intesa come lezione di prudenza e di lungimiranza alla critica tutta laica della casualità. A compensare questo pessimismo totale, la convinta proposta di un diverso modo di interpretare e di scrivere la storia. Il primo dialogo - la Première journée - articola il dibattito «maieutico» sul tema del merito e della fortuna, sull'intelligenza priva di virtù, sui «bons mots», che possono arrecare credito o discredito, e sull'audacia e la circospezione, di cui Saint-Réal rovescia, discreditandoli, gli assunti machiavelliani oltre a puntare l'analisi non più sul principe ma sui cortigiani. La Deuxième journée affronta la questione dell'ipocrisia politica e dell'accorta scelleratezza attraverso la storia dell'alleanza di Tolomeo, padre di Cleopatra, con la Repubblica romana, e attraverso i ritratti di Pompeo e di Crasso: questo racconto di Césarion fa entrare il lettore direttamente in quello che Federico Corradi chiama giustamente il laboratorio dello storico, lo spazio in cui prende forma una narrazione storica che svela segreti politici e «secrets du cœur», che mette a confronto - anzi: sintonizza - quel «palais labyrintique» che è per Saint-Réal l'animo dell'uomo e quella «maison fort irrégulière» che è la corte. Il terzo dialogo è interamente dedicato ad Attico, l'amico di Cicerone. Ancora una volta, ecco all'opera lo scalpello di Saint-Réal, che anatomizza qui e disgrega l'ideale dell'amicizia e quello dell'honnêteté, additando nell'arte di saper viver di personaggi altrimenti mediocri le ragioni del successo e delle belle reputazioni, in realtà «fantômes de réputation». L'ultima Journée, in parallelo con la prima, adotta l'andamento, scrive Corradi, dell'«anecdote détachée», sintetizzata in un gesto o una parola - un segno - che lo storico interpreta come «acte de langage», e fa così luce sul carattere morale del personaggio. Significativo allora, in questo dialogo, il discorso, in contrasto con le teorie dell'epoca, sulla pittura, la quale, spiega Césarion al suo allievo, è statica e non può quindi rappresentare se non in modo imperfetto ciò che è movimento: battaglie, tempeste, incendi, che i pittori invece tanto prediligono. saranno prive di seguito, è la valenza suggestiva e simbolica del dipinto, tale da destare 
nello spettatore interrogazione e riflessione. Il quadro dinanzi al quale si fermano Césarion e il suo giovane amico raffigura Diogene, coperto di stracci, che con una mano si appoggia ad un bastone mentre porge l'altra a una statua splendidamente vestita; accanto, una botte - «emblema» del personaggio - coricata e vuota, di cui si intravvede il fondo. La lezione morale non consiste tanto nel quadro in sé e in quel che raffigura, ma nell'invito a interrogarsi sul suo significato, a decifrarne il segreto: il disinteressamento di Diogene che tende la mano a chi nulla può offrirgli. Soggetto noioso, però, contesta l'allievo, il quale confessa di non avere la pazienza di fermarsi a osservarlo e sondarne il messaggio. E Césarion gli ricorda allora che proprio la virtù della pazienza, più di ogni altra, è importante per vivere a corte, dove a nulla vale il merito. «Patientia animi occultas divitias habet...».

6 Dobbiamo alla bella collana diretta da Patrick Dandrey per Hermann e alla solida cultura e intelligenza critica di Federico Corradi la riscoperta di questo piccolo capolavoro di fine Seicento, utile a rimettere in prospettiva il discorso sul legame tra storia e morale quale fu rielaborato tra Rinascimento e Seicento, ma ugualmente a comprendere alcuni sviluppi di questo stesso discorso nel secolo a venire. 